\title{
EVALUATION AND GENERALIZATION OF 13 MASS-TRANSFER EQUATIONS FOR DETERMINING FREE WATER EVAPORATION
}

\author{
V. P. SINGH ${ }^{1}$ AND C.-Y. XU ${ }^{2 *}$ \\ ${ }^{1}$ Department of Civil and Environmental Engineering, Louisiana State University, Baton Rouge, LA 70803-6405, USA \\ ${ }^{2}$ Division of Hydrology, Uppsala University, Norbyvägen 18B, S-75236 Uppsala, Sweden
}

\begin{abstract}
Thirteen equations based on the mass-transfer method for determining free water evaporation were expressed in seven generalized equations. These seven equations were then compared with pan evaporation at four climatological stations in north-western Ontario, Canada. The comparisons were based on monthly evaporation. Equations were compared by calibrating them on the entire data sets as well as by calibrating on part of the data and then verifying them on the remainder of the data. The results of comparison showed that all equations were in reasonable agreement with observed evaporation, and that the effect of wind velocity on monthly evaporation was marginal. However, when an equation with parameters obtained at one site was applied to compute evaporation at another site, the computed evaporation was not in good agreement with observed values. (C) 1997 by John Wiley \& Sons, Ltd.
\end{abstract}

Hydrological Processes, vol. 11, 311-323 (1997).

(No. of Figures: 6 No. of Tables: 3 No. of Refs: 39$)$

KEY WORDS evaporation; free water surface; mass-transfer method; north-western Ontario

\section{INTRODUCTION}

Evaporation estimates are needed in a wide array of problems in hydrology, agronomy, forestry and land resources planning, such as water balance computation, irrigation management, river flow forecasting, investigation of lake chemistry, ecosystem modelling, etc. Of all the components of the hydrological cycle, evaporation is perhaps the most difficult to estimate owing to complex interactions between the components of the land-plant-atmosphere system.

There exists a multitude of methods for measurement and estimation of evaporation. Overviews of many of these methods are found in numerous reviews, (see, for example, Brutsaert, 1982; Singh, 1989; Morton, 1990, 1994). Very recently, Panu and Nguyen (1994) evaluated four methods of estimating mean areal evaporation in north-western Ontario, Canada; whereas Winter et al. (1995) compared 11 equations for determining evaporation for a small lake in the north-central United States. Morton (1990) presented a critique of evaporation measurement methods.

The methods for determining evaporation can be grouped into several categories, including: (i) empirical (e.g. Kohler et al., 1995), (ii) water budget (e.g. Guitjens, 1982), (iii) energy budget (e.g. Fritschen, 1966), (iv) mass transfer (e.g. Harbeck, 1962), (v) combination (e.g. Penman, 1948) and (vi) measurement (e.g. Young, 1947).

Empirical methods relate either pan evaporation, actual lake evaporation or lysimeter measurements to meteorological factors using regression analyses. The weakness of these empirical methods is that they have a limited range of applicability because (i) their variables may not be easily measurable in other places, or some existing data may not be utilized; (ii) they are usually accurate only in a limited range, for their model structure may be only partially correct; and (iii) it is difficult to compare one method with another due to

\footnotetext{
* Corresponding author.
} 
method-specific model variables; for example, the requirements for measurement of temperature and wind speed may be at different heights above the water or ground surface.

The water budget methods are simple in theory, but rarely produce reliable results in practice. The main difficulty is that some of the variables, such as seepage rate in a water system, are hard to measure (Singh, 1989). Morton (1990) has summarized other problems associated, in general, with such methods.

The energy budget methods (including the Penman combination methods) are reliable in theory and suitable for research purposes only in small areas, because of their requirements for detailed meteorological data, such as net radiation, sensible heat flux, etc. Their practical utility for larger lakes is limited. Although McCulloch (1965) presented tables for rapid computation of evaporation by the Penman method, Schulz (1962) presented a graphical procedure for using this model, and Van Bavel (1968) presented a simplified generalized model, it still requires an evaluation of the net radiation which is not so easily obtainable for many applied engineering problems.

The mass-transfer (aerodynamic) based methods utilize the concept of eddy motion transfer of water vapour from an evaporating surface to the atmosphere. All such methods are based on Dalton's law. The mass-transfer methods give satisfactory results in many cases (Thornthwaite and Holzman, 1939; Meyer, 1944; Sverdrup, 1946; Sutton, 1949; Jensen, 1973) and normally use easily measurable variables and have simple model form. However, wind speed and air temperature have been measured at inconsistent heights, resulting in a large number of equations with similar or identical structure. The wide ranging inconsistency in meteorological data collection procedures and standards has given rise to over 100 evaporation formulae and has made it impossible for a comparative study (Helfrich et al., 1982; Panu and Nguyen, 1994).

It is difficult to select the most appropriate evaporation measurement methods for a given study. This is partly because of the availability of many equations for determining evaporation, the wide range of data types needed and the wide range of expertise needed to use the various equations correctly. More importantly, objective criteria for model selection are lacking. Consequently, the conditions under which one evaporation method would be more suitable are not always spelled out.

Recognizing the above concerns, an attempt is made in this paper to analyse and compare the various forms of the existing, simple popular models belonging to the category of the mass-transfer method, and to develop a generalized model form from these methods. This is because the mass-transfer approaches generally are easiest to use and often are the only practical method available. This generalized model should possess the following characteristics: (i) be analytical and simple, (ii) its variables should be easily measurable, (iii) it should consist of the most important influencing factors, (iv) other simple models should be special cases of the generalized one and (v) the model parameters should be easily estimated with acceptable accuracy.

\section{MODEL DEVELOPMENT}

\section{Discussion of existing models}

Clearly, evaporation depends on the supply of heat energy and vapour pressure gradient, which, in turn, depend on meteorological factors such as temperature, wind speed, atmospheric pressure, solar radiation, quality of water and the nature and shape of the evaporating surface (Morton, 1968). These factors also depend on other factors, such as geological locations, seasons, etc. Thus, the process of evaporation is rather complicated. A complete physical model may be too difficult to develop since there exist many factors that are not controllable and measurable.

The mass-transfer method is one of the oldest methods (Dalton, 1802; Meyer, 1915; Penman, 1948) and is still an attractive method for estimating free water surface evaporation because of its simplicity and reasonable accuracy. The mass-transfer methods are based on the Dalton equation, which for free water surface can be written as:

$$
E_{0}=C\left(e_{\mathrm{s}}-e_{\mathrm{a}}\right)
$$

where $E_{0}$ is free water surface evaporation, $e_{\mathrm{s}}$ is the saturation vapour pressure at the temperature of the water surface, $e_{\mathrm{a}}$ is the vapour pressure in the air and $C$ is aerodynamic conductance. The term $e_{\mathrm{a}}$ is also 
equal to the saturation vapour pressure at the dew point temperature. Sometimes $C$ is taken as $C=1 / r_{\mathrm{a}}$, where $r_{\mathrm{a}}$ is the aerodynamic resistance. The parameter $C$ can also be construed as the amount of water evaporated from unit vapour pressure deficit. Although $C$ depends on the horizontal wind speed, surface roughness and thermally induced turbulence, it is normally assumed to be dependent on wind speed, $u$. Therefore, Equation (1) is expressed as:

$$
E_{0}=f(u)\left(e_{\mathrm{s}}-e_{\mathrm{a}}\right)
$$

where $f(u)$ is the wind function. This function depends on, among other factors, the observational heights of the wind speed and vapour pressure measurements. Although the two heights need not be the same, the same experimental layout must be used for a particular value of the function. The mass-transfer method has had wide application in the estimation of lake evaporation and many empirical formulae have been derived based on this approach (Singh, 1989). Examples of empirical equations of this type are included in Table I [Equations (3)-(15)] which lists 13 relatively simple and commonly used evaporation equations.

An inspection of the above mass-transfer-based equations reveals that the three major meteorological factors considered to affect evaporation are vapour pressure gradient, wind speed and temperature. The air pressure, fluid density and water surface elevation for a given location may not greatly affect the rate of evaporation. Table I also shows that specific formulae have resulted from the analysis of limited and sitespecific meteorological data. The data collection procedures are not only varied but are frequently inconsistent. Usually, such inconsistencies are a major source of site-specific modifications and adaptations of these types of equations. Specifically, the elevations at which temperature and vapour pressure are measured vary widely. As a result, estimates of moisture gradient and wind velocity are affected.

Table I. Some mass-transfer-based evaporation equations for estimation of evaporation

\begin{tabular}{|c|c|c|c|}
\hline Author & Equation & No. & Remarks \\
\hline Dalton (1802) & $E(\mathrm{in} . / \mathrm{mo})=a\left(e_{\mathrm{s}}-e_{\mathrm{a}}\right)$ & (3) & $\begin{array}{l}a=15 \text { for small, shallow } \\
\text { water, and } a=11 \text { for } \\
\text { large deep water }\end{array}$ \\
\hline Fitzgerald (1886) & $E(\mathrm{in} . / \mathrm{mo})=(0.4+0 \cdot 199 u)\left(e_{\mathrm{s}}-e_{\mathrm{a}}\right)$ & (4) & \\
\hline Meyer (1915) & $E(\mathrm{in} . / \mathrm{mo})=11(1+0 \cdot 1 u)\left(e_{\mathrm{s}}-e_{\mathrm{a}}\right)$ & (5) & $\begin{array}{l}e_{\mathrm{a}} \text { is measured at } 30 \mathrm{ft} \\
\text { above the surface }\end{array}$ \\
\hline Horton (1917) & $E(\mathrm{in} . / \mathrm{mo})=0.4\left[(2-\exp (-2 u))\left(e_{\mathrm{s}}-e_{\mathrm{a}}\right)\right]$ & (6) & \\
\hline Rohwer (1931) & $\begin{array}{l}E(\mathrm{in} . / \mathrm{da})=0.77\left(1.465-0.0186 p_{\mathrm{b}}\right) \\
\quad(0.44+0.118 u)\left(e_{\mathrm{s}}-e_{\mathrm{a}}\right)\end{array}$ & (7) & $\begin{array}{l}p_{\mathrm{b}}=\text { barometric } \\
\text { pressure in in. of } \mathrm{Hg} .\end{array}$ \\
\hline Penman (1948) & $E($ in. $/ \mathrm{da})=0.35\left(1+0.24 u_{2}\right)\left(e_{\mathrm{s}}-e_{\mathrm{a}}\right)$ & (8) & \\
\hline Harbeck et al. (1954) & $\begin{array}{l}E(\mathrm{in} . / \mathrm{da})=0.0578 u_{8}\left(e_{\mathrm{s}}-e_{\mathrm{a}}\right) \\
E(\mathrm{in} . / \mathrm{da})=0.0728 u_{4}\left(e_{\mathrm{s}}-e_{\mathrm{a}}\right)\end{array}$ & (9) & \\
\hline Kuzmin (1957) & $E($ in. $/ \mathrm{mo})=6 \cdot 0\left(1+0 \cdot 21 u_{8}\right)\left(e_{\mathrm{s}}-e_{\mathrm{a}}\right)$ & (10) & \\
\hline Harbeck et al. (1958) & $\begin{array}{l}E(\text { in. } / \mathrm{da})=0.001813 u\left(e_{\mathrm{s}}-e_{\mathrm{a}}\right) \\
\quad\left(1-0.03\left(T_{\mathrm{a}}-T_{\mathrm{w}}\right)\right)\end{array}$ & $(11)$ & $\begin{array}{l}T_{\mathrm{a}}=\text { average air } \\
\text { temperature, }{ }^{\circ} \mathrm{C}+1.9^{\circ} \mathrm{C} ; \\
T_{\mathrm{w}}=\text { average water } \\
\text { surface temperature, },{ }^{\circ} \mathrm{C} .\end{array}$ \\
\hline Konstantinov (1968) & $\left.E(\mathrm{in} . / \mathrm{da})=0.024\left(t_{\mathrm{w}}-t_{2}\right) / u_{1}+0.166 u_{1}\right)\left(e_{\mathrm{s}}-e_{\mathrm{a}}\right)$ & (12) & \\
\hline Romanenko (1961) & $E(\mathrm{~cm} / \mathrm{mo})=0.0018\left(T_{\mathrm{a}}+25\right)^{2}(100-h n)$ & (13) & $h n=$ relative humidity \\
\hline Sverdrup (1946) & $E(\mathrm{~cm} / \mathrm{s})=\left(0.623 \rho K_{0}^{2} u_{8}\left(e_{0}-e_{8}\right)\right) / p\left([\ln 800 / z]^{2}\right)$ & (14) & $\begin{array}{l}K_{0}=\text { von Karman's const } \\
\rho=\text { density of air } \\
p=\text { atmospheric pressure }\end{array}$ \\
\hline $\begin{array}{l}\text { Thornthwaite and } \\
\text { Holzman (1939) }\end{array}$ & $E(\mathrm{~cm} / \mathrm{s})=\left(0.623 \rho K_{0}^{2}\left(u_{8}-u_{2}\right)\left(e_{2}-e_{8}\right)\right) /\left(p[\ln (800 / 200)]^{2}\right)$ & $(15)$ & \\
\hline
\end{tabular}

The wind speed (monthly mean) $u$ is measured in miles per hour and vapour pressure $e$, in inches of $\mathrm{Hg}$. The subscripts attached to $u$ refer to height in metres at which the measurements are taken; no subscript refers to measurements near the ground or water surface 


\section{Generalization of the Methods}

From the 13 equations listed in Table I it can be seen that evaporation is proportional to vapour pressure gradient $\left(e_{\mathrm{s}}-e_{\mathrm{a}}\right)$ and also proportional to wind speed, but the relationship between evaporation and temperature is not explicitly included in most of them. Because the water surface temperature is usually not available, the saturation vapour pressure at the air temperature, $e_{0}$, has been used in place of the saturation vapour pressure at the water surface temperature, $e_{\mathrm{s}}$, by some investigators (e.g. Visentini, 1936; Haude, 1955; Hounam, 1971). For the same reason, the term $\left(e_{\mathrm{s}}-e_{\mathrm{a}}\right)$ in the equations in Table I has been developed in this study using $\left(e_{0}-e_{\mathrm{a}}\right)$, the saturation deficit of the air. The saturation vapour pressure, $e_{0}$, and actual vapour pressure $e_{\mathrm{a}}$ are calculated, respectively, from air temperature and dew point temperature using the equation presented by Bosen (1960). Likewise, the water surface temperature used in the equations is replaced by the dew point temperature, $T_{\mathrm{d}}$.

The equations given in Table I can be generalized in the form:

$$
E=f(u) g(e) h(T)
$$

where $f(u), g(e)$ and $h(T)$ are wind speed, vapour pressure and temperature functions, respectively. When $f(u)=a, g(e)=\left(e_{0}-e_{\mathrm{a}}\right)$ and $h(T)=1$, Equation (16) leads to Equation (3); when $f(u)=a u, g(e)=$ $\left(e_{0}-e_{\mathrm{a}}\right)$ and $h(T)=1$, Equation (16) is identical to Equation (9); when $f(u)=a(1+b u), g(e)=\left(e_{0}-e_{\mathrm{a}}\right)$ and $h(T)=1$, Equation (16) is the same as Equations (4), (5), (8) and (10); when $f(u)=a\left(1-e^{-u}\right)$, $g(e)=\left(e_{0}-e_{\mathrm{a}}\right)$ and $h(T)=1$, Equation (16) equals Equation (6); Equation (13) can be considered as a special form of Equation (16) when $f(u)=a, g(e)=(100-h n)$ and $h(T)=\left(T_{\mathrm{a}}-25\right)^{2}$; Equation (11) is a special case of Equation (16) when $f(u)=a u, g(e)=\left(e_{0}-e_{\mathrm{a}}\right)$ and $h(T)=1-c\left(T_{\mathrm{a}}-T_{\mathrm{d}}\right)$.

The Sverdrup (1946) equation can be considered as a special case of Equation (16) as well, since fluid density and air pressure normally vary little over time at a given place. The Thornthwaite and Holzman (1939) equation is similar to the Sverdrup equation except that the former has the possible drawback that if wind speeds $u_{8} \cong u_{2}$, the evaporation becomes zero, which usually is not true.

In general, the following equation forms can be presented for the equations shown in Table I.

$$
\begin{aligned}
& \text { (A) } E=a \cdot\left(e_{0}-e_{\mathrm{a}}\right) \\
& \text { (B) } E=a \cdot u\left(e_{0}-e_{\mathrm{a}}\right) \\
& \text { (C) } E=a \cdot(1-\exp (-u)) \cdot\left(e_{0}-e_{\mathrm{a}}\right) \\
& \text { (D) } E=a \cdot(1+b \cdot u) \cdot\left(e_{0}-e_{\mathrm{a}}\right) \\
& \text { (E) } E=a \cdot u \cdot\left(e_{0}-e_{\mathrm{a}}\right) \cdot\left(1-b \cdot\left(T_{\mathrm{a}}-T_{\mathrm{d}}\right)\right) \\
& \text { (F) } E=a \cdot\left(T_{\mathrm{a}}+25\right)^{2} \cdot(100-h n) \\
& \text { (G) } E=a \cdot(1+b \cdot u) \cdot\left(e_{0}-e_{\mathrm{a}}\right) \cdot\left(1-c \cdot\left(T_{\mathrm{a}}-T_{\mathrm{d}}\right)\right)
\end{aligned}
$$

where $a, b$ and $c$ are parameters, $h n$ is the relative humidity and other symbols have the same meaning as before.

\section{MODEL EVALUATION}

\section{Considerations for comparative evaluation}

It is generally accepted that empirical formulae, as presented in Table I, may be reliable in the areas and over the periods for which they were developed, but large errors can be expected when they are extrapolated to other climatic areas without recalibrating the constants involved in the formulae (Hounam, 1971). In order to alleviate these difficulties, a comparative study was carried out to evaluate the seven generalized equation forms $[(A)-(G)]$ instead of comparing the original formulae shown in Table I. This consideration has, at least, two advantages: (i) for a specific site of interest, it is the form of a given model that is more important (useful) than the predetermined values of the constants using the meteorological data measured at a 


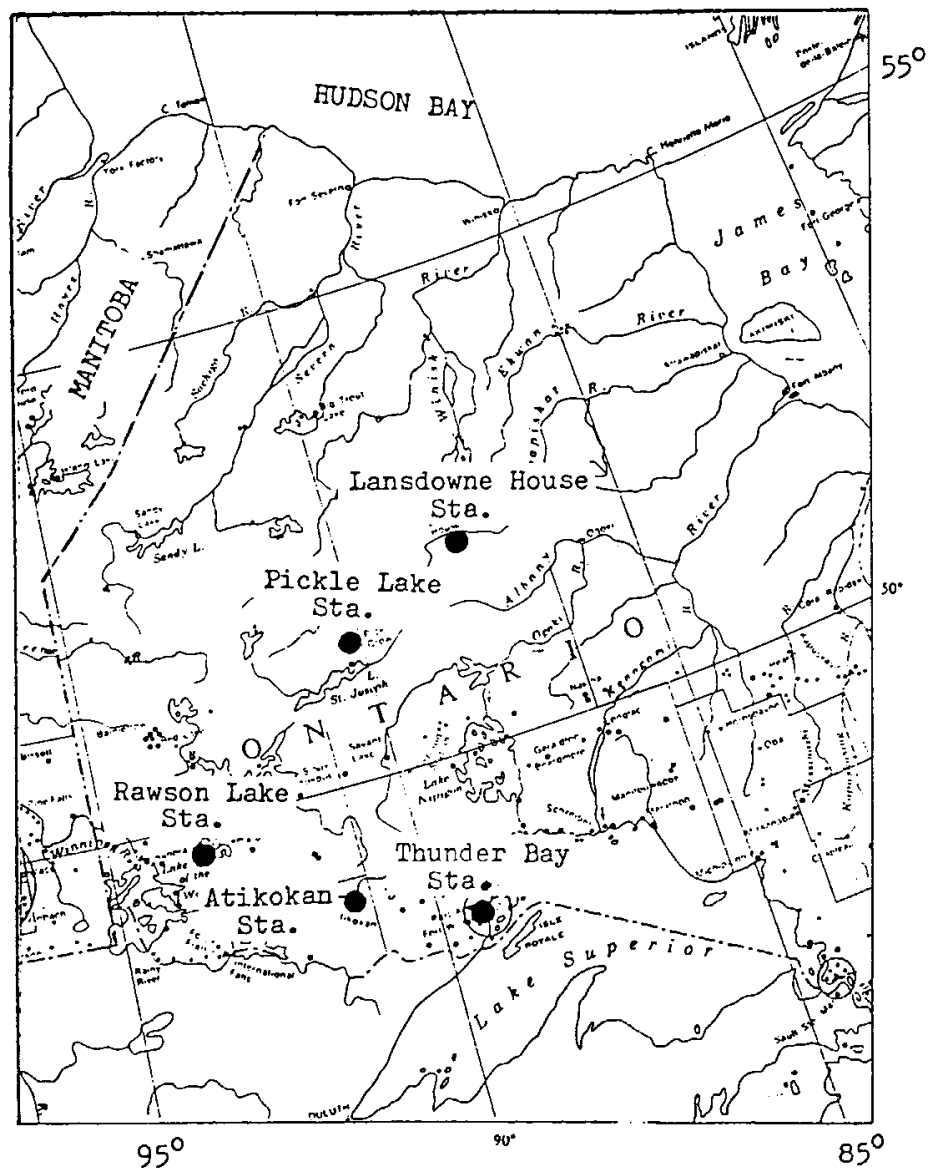

Figure 1. Geographical location of selected climatological stations in north-western Ontario (reproduced from Panu and Nguyen, 1994)

previously reported site; and (ii) it allows a comparison of all the model forms using the standard meteorological data measured at consistent heights and for the same periods.

In this study, the following units for different variables were used: evaporation, $E$, in $\mathrm{cm} / \mathrm{month}$; saturation and actual vapour pressures, $e_{0}$ and $e_{\mathrm{a}}$, in mbar; wind speed measured at $2 \mathrm{~m}$ height, $u$, in $\mathrm{km} /$ hour; and air temperature, $T_{\mathrm{a}}$, and dew point temperature, $T_{\mathrm{d}}$, measured at $2 \mathrm{~m}$ height, in ${ }^{\circ} \mathrm{C}$.

\section{Study Region and Data}

Four climatological stations were used for comparative evaluation of the aforementioned evaporation equations. These stations are located in north-western Ontario, Canada. The region is geographically defined by the borders of Manitoba, United States, Hudson Bay, James Bay and the easterly border as shown in Figure 1. The physiography of the area is typified by the occurrence of numerous lakes. It would be better to select lakes from different climatic settings, but this was not done owing to lack of data. According to Panu and Nguyen (1994), the mean annual precipitation for the region varies from a maximum of over $800 \mathrm{~mm}$ to less than $550 \mathrm{~mm}$, with an average value of $650 \mathrm{~mm}$. Mean annual temperature ranges from $-4^{\circ} \mathrm{C}$ to more than $3^{\circ} \mathrm{C}$. The pertinent information on these stations is provided in Table II. Evaporation in this region is most significant during the summer season (June-September) and relatively insignificant in October-May because the temperature fluctuates near freezing point during these months. Therefore, the mean monthly evaporation rates were only computed and compared for the months of June, July, August and September of each year. 
Table II. General information on climatological stations in north-western Ontario

\begin{tabular}{|c|c|c|c|c|c|}
\hline \multirow[t]{2}{*}{ Station } & \multicolumn{4}{|c|}{ Mean monthly values (Jun-Sept) } & \multirow[t]{2}{*}{ Period } \\
\hline & $\begin{array}{l}\text { Air temp. } \\
\quad\left({ }^{\circ} \mathrm{C}\right)\end{array}$ & $\begin{array}{l}\text { Dew point } \\
\text { temp. }\left({ }^{\circ} \mathrm{C}\right)\end{array}$ & $\begin{array}{l}\text { Wind velocity } \\
\qquad(\mathrm{km} / \mathrm{h})\end{array}$ & $\begin{array}{l}\text { Class A pan } \\
\text { evap. (mm) }\end{array}$ & \\
\hline Atikokan & $14 \cdot 53$ & 9.92 & 7.63 & $126 \cdot 88$ & $1968-1982$ \\
\hline Lansdown House & $13 \cdot 85$ & 8.68 & 14.97 & 115.68 & $1971-1982$ \\
\hline Pickle Lake & $13 \cdot 62$ & $8 \cdot 13$ & $12 \cdot 80$ & $117 \cdot 18$ & $1977-1982$ \\
\hline Rawson Lake & 15.98 & $9 \cdot 25$ & $9 \cdot 61$ & 130.49 & $1971-1982$ \\
\hline
\end{tabular}

\section{Parameter Estimation and Evaluation Criteria}

The application of a model includes the specification of model type, determination of the parameters and verification of the model performance. In this section only a limited number of items are discussed. A full account is given by $\mathrm{Xu}(1992)$.

To estimate model parameters, an 'automatic optimization' method was used, and the optimality criterion adopted was the least-square error between measured and computed free water evaporation. Let $E_{\mathrm{t}, \mathrm{obs}}$ be the observed evaporation, and $E_{\mathrm{t}, \mathrm{comp}}$ the computed evaporation, which is a function of model parameters. Then, the objective function, $E R$, to be minimized can be expressed as

$$
E R=\Sigma\left(E_{\mathrm{t}, \mathrm{obs}}-E_{\mathrm{t}, \mathrm{comp}}\right)^{2}=\operatorname{minimum~SSQ}
$$

where summation is over the number of observations. Optimization of model parameters is the minimization of the objective function in Equation (17).

To check the significance of the parameters and to provide a quantitative comparison between the parameter values of the same model over different stations, confidence intervals at $95 \%$ significance level were computed for the 'best' parameters, $a_{i}$, as

$$
a_{i} \pm 1.96 \sigma_{i}
$$

where $\sigma_{i}$ is the standard deviation of parameter $a_{i}$.

Various measures of goodness-of-fit have been proposed (e.g. Nash and Sutcliffe, 1970). This study employed the relative error between the evaporation determined by the seven generalized equations and the evaporation observed by Class A pan, i.e.

$$
\text { relative error }(\%)=\frac{\left(E_{\mathrm{t}, \mathrm{comp}}-E_{\mathrm{t}, \mathrm{obs}}\right)}{E_{\mathrm{t}, \mathrm{obs}}} * 100
$$

\section{RESULTS AND DISCUSSION}

\section{Model Calibration}

The seven generalized equations and the statistical methodology discussed in the previous section were applied to the four climatological stations. The optimized parameter values together with the $95 \%$ confidence interval for each model and station combination are presented in Table III. In the last column of the table, the regionally averaged parameter values are also shown. The relative errors, as calculated by Equation (19) are plotted in Figure 2 for each climatological station. From an examination of Table III and Figure 2 one finds the following.

(1) Significant differences are expected for parameter values of the same model among different stations (Table III). Spatial variability of the parameters is significant and, in general, the parameter values of the same model increase gradually from north to south with the smallest values found for the Lansdown House station and the biggest for the Atikokan station in most cases. 
Table III. Comparison of model parameter values for different stations

\begin{tabular}{|c|c|c|c|c|c|c|}
\hline \multirow[t]{2}{*}{ Model } & \multirow[t]{2}{*}{ Parameter } & \multicolumn{4}{|c|}{ Stations } & \multirow{2}{*}{$\begin{array}{l}\text { Average of the } \\
\text { four stations }\end{array}$} \\
\hline & & Atikokan & Lansdown & Pickle Lake & Rawson Lake & \\
\hline (A) & $a$ & $2.848+0.071$ & $1.295 \pm 0.076$ & $2 \cdot 302 \pm 0.111$ & $1.982 \pm 0.044$ & $2 \cdot 107$ \\
\hline (B) & $a$ & $\overline{1.334 \pm 0.047}$ & $0.5861 \pm 0.017$ & $0 . \overline{6513 \pm 0.039}$ & $0 . \overline{7314 \pm 0.019}$ & 0.826 \\
\hline (C) & $a$ & $\overline{3.262 \pm 0.082}$ & $2.346 \pm 0.076$ & $2.380 \pm 0.115$ & $2.128 \pm 0.046$ & 2.529 \\
\hline \multirow{2}{*}{ (D) } & $a$ & $2.504+0.508$ & ${ }^{*} 0.3823 \pm 0.706$ & $2 \cdot 112 \pm 0.967$ & $1.507 \pm 0.575$ & 1.626 \\
\hline & $b$ & $* 0.0653+0.103$ & ${ }^{*} 1.280 \pm 1.62$ & ${ }^{*} 0.0258 \pm 0.142$ & ${ }^{*} 0.1167 \pm 0.185$ & $0 \cdot 372$ \\
\hline \multirow[t]{2}{*}{ (E) } & $a$ & $1.832 \pm 0.256$ & $0.6835 \pm 0.081$ & $\overline{0.8496 \pm 0.173}$ & $0.8015 \pm 0.110$ & 1.042 \\
\hline & $b$ & $0.0537+0.018$ & $0.0246+0.016$ & $0.0366+0.024$ & $* \frac{0.0119+0.019}{0.019}$ & 0.032 \\
\hline (F) & $+a$ & $1.982 \pm 0.043$ & $1.917 \pm 0.063$ & $1.922 \pm 0.127$ & $1.834 \pm 0.066$ & 1.914 \\
\hline \multirow{3}{*}{ (G) } & $a$ & $3 \cdot 143 \pm 0.644$ & $1.185 \pm 0.953$ & $2.990 \pm 1.21$ & $1.682 \pm 0.652$ & $2 \cdot 250$ \\
\hline & $b$ & $* 0 \cdot 0880+0.107$ & $* 0 \cdot 3680+0.464$ & $* 0.0140+0.109$ & ${ }^{*} 0.1144+0.179$ & 0.146 \\
\hline & $c$ & $0.0467 \pm 0.015$ & $0.0352 \pm 0.016$ & $0.0415 \pm 0.017$ & ${ }^{*} 0.0136 \pm 0.014$ & 0.034 \\
\hline
\end{tabular}

Notes:

(1) ${ }^{+}$parameter values of model $\mathrm{F}$ have been scaled up by 10000 .

(2) * means the parameter is insignificant, i.e. zero is included in the confidence interval.

(3) underline means there is significant difference from the regionally averaged value, i.e. the regionally averaged value does not lay in the confidence interval of the parameter for that station

(2) All methods yielded comparable and good results when the parameters were calibrated using local meteorological variables (Figure 2). The mean seasonal per cent error (from June to September) varies from $0.07 \%$ (model $\mathrm{G}$ for Rawson Lake station) to $3 \cdot 10 \%$ (model B for Pickle Lake station). The monthly per cent error varies from $0.03 \%$ (model A for Rawson Lake station in September) to $14.91 \%$ (model E for Atikokan station in September). The equations with more terms and parameters involved did not exhibit a tendency to perform better than did model A, with fewer parameters. This conclusion is valid for the monthly time-scale at least.

Since the aim of the above-mentioned equations is to estimate evaporation on the basis of meteorological variables, perhaps the first and most striking comparison that can be made on the performance of an equation can be seen from the plot of the observed and computed monthly evaporation. An example is shown in Figure 3 for the Atikokan station and Equation (G), which shows a very good agreement between the observed and computed evaporation series. Similar good agreements between the observed and computed monthly evaporations for other station-equation combinations can be expected, as can be seen from Figure 2, where a small range of relative errors is shown for all station-equation combinations.

(3) Parameter $b$ in models D and $\mathrm{G}$ is found to be insignificant for all the stations (Table III). This again shows that monthly mean wind speed is not a significant factor. The term $f(u)=a(1+b u)$ in Equation (16) seems over-parameterized, which can be simplified to $f(u)=a u$ or $f(u)=$ $a \cdot(1-\exp (-u))$, or even to $f(u)=a$, with more or less the same explanatory power.

\section{Significance of Different Terms in Equation (1)}

As discussed in previous sections, the mass-transfer methods are based on the Dalton equation. Its general form for free water surface could be written as Equation (1). Evaporation equations of this type differ by their functions in expressing $C$ - the aerodynamic conductance. Seven forms of the $C$ functions are explicitly written in Equations (A)-(G). A test was done for the above-mentioned, seven generalized equations to check the significance of different $C$ functions and the saturation deficit term $g(e)=\left(e_{0}-e_{\mathrm{a}}\right)$. For illustrative purposes, the results for the Atikokan station are shown in Figure 4. In order to have the same magnitude, their relative values, i.e. the actual values for each month divided by the mean value for the entire period, were used. It is seen that the saturation deficit of the air, i.e. term $g(e)=\left(e_{0}-e_{\mathrm{a}}\right)$, is the dominant factor in estimating monthly free water surface evaporation, resulting in an excellent agreement between this term and the computed evaporation; while the $C$ function is pretty much constant in time and 

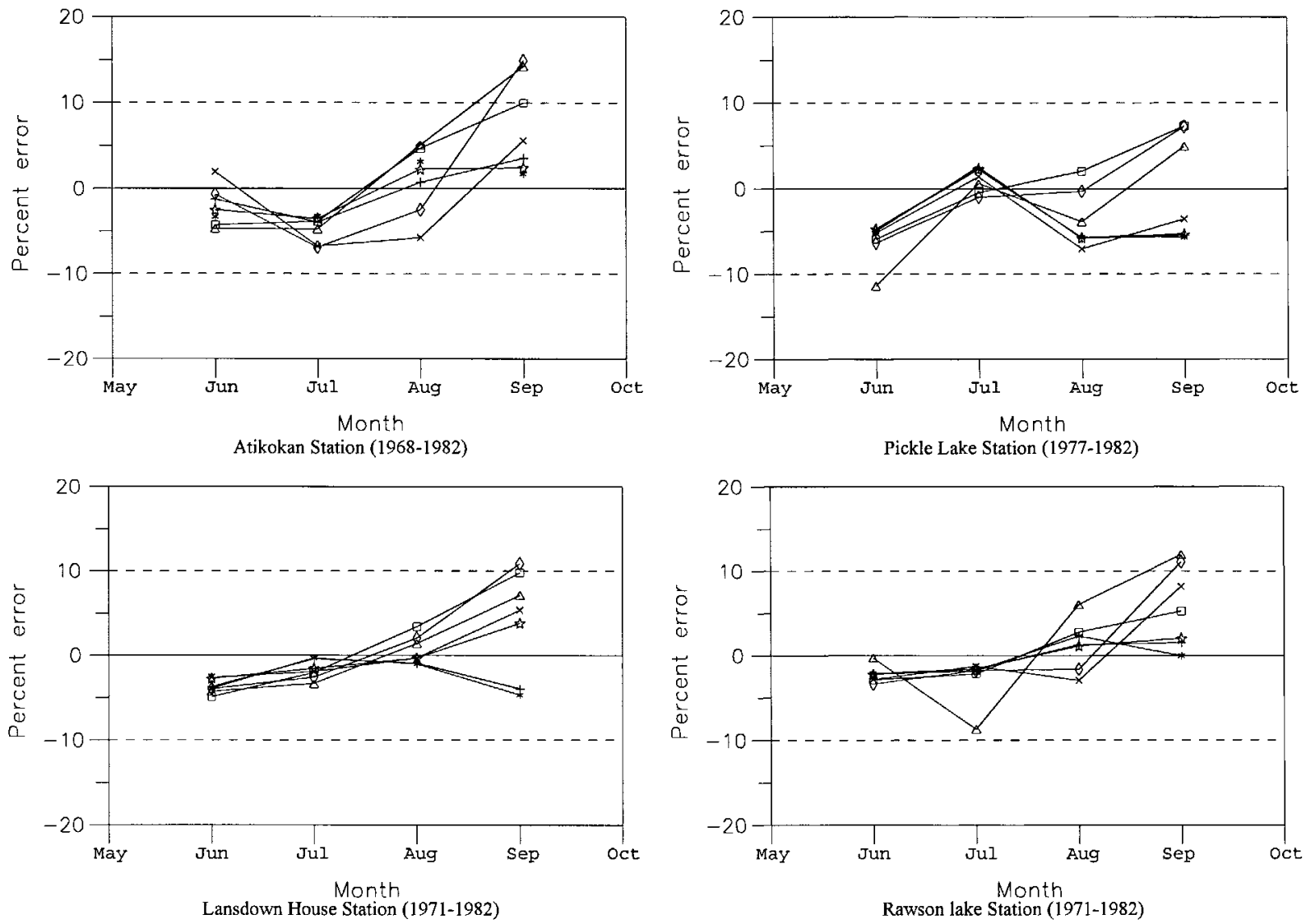

Figure 2. Per cent error in evaporation estimates at different climatological stations using locally calibrated parameters. [Line with asterisk for Equation (A), line with cross for Equation (B), line with plus for Equation (C), line with star for Equation (D), line with rhomb for Equation (E), line with triangle for Equation $(F)$, line with square for Equation $(\mathrm{G})]$

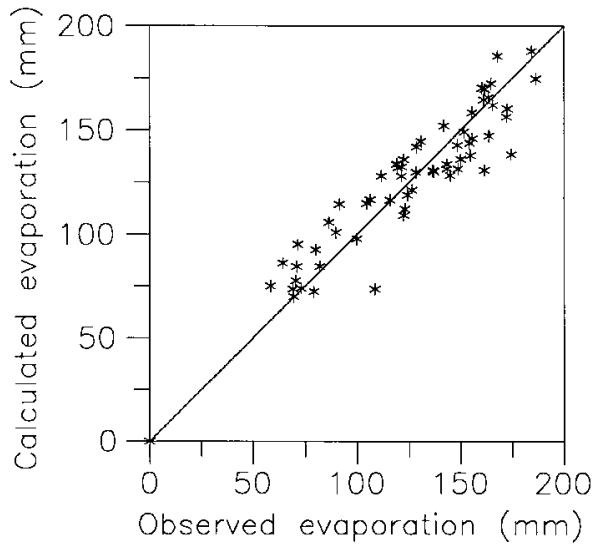

Figure 3. Comparison between observed and computed monthly evaporation for the Atikokan station with Equation (G)

has a very narrow range with the exception of Equation $(F)$. This is the only equation in which the relative humidity, $h n$, was used instead of the saturation deficit term $g(e)=\left(e_{0}-e_{\mathrm{a}}\right)$. Moreover, this equation was originally developed for estimating potential evapotranspiration (Romanenko, 1961) rather than free water evaporation as the other equations did. 

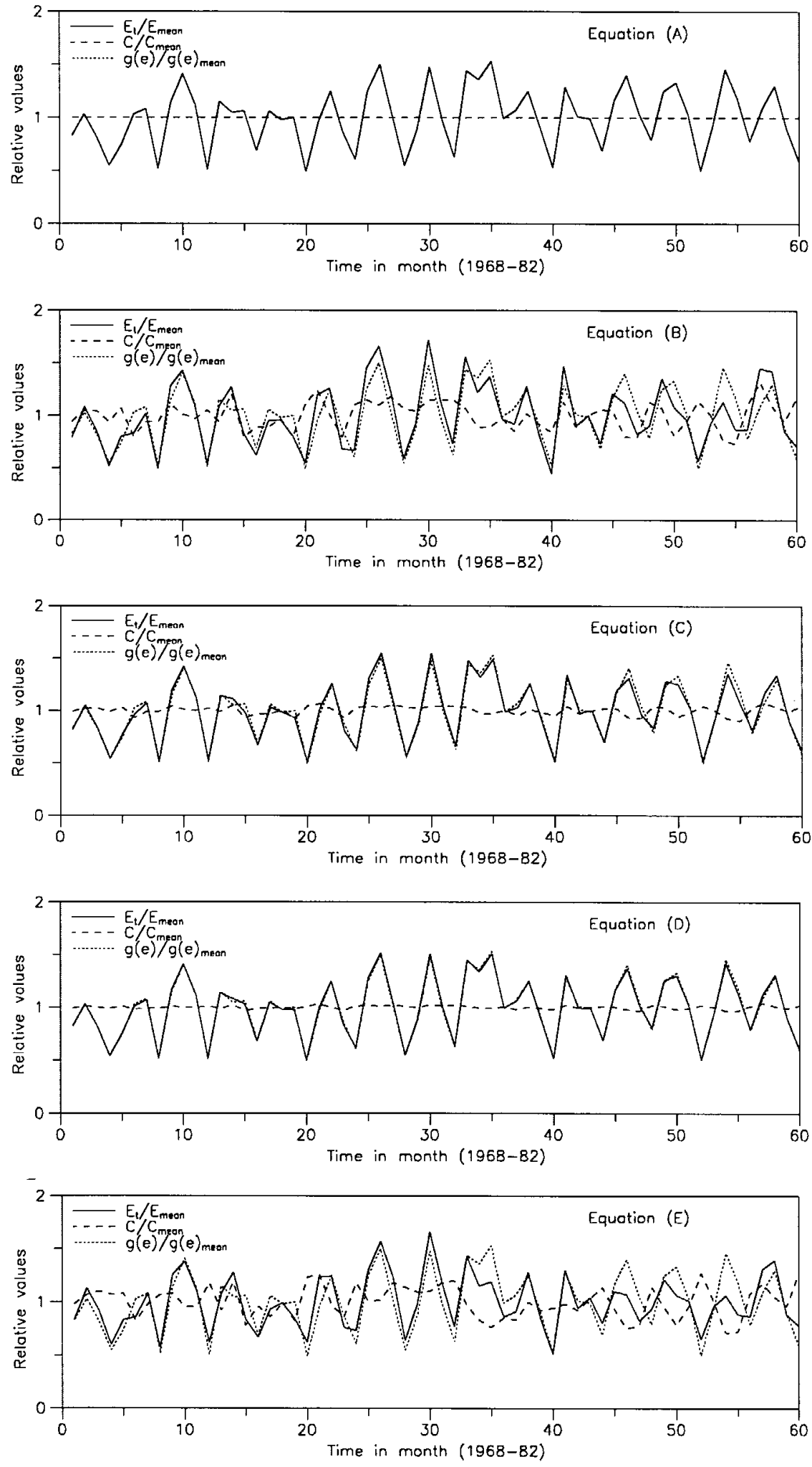

Figure 4. Caption overleaf 

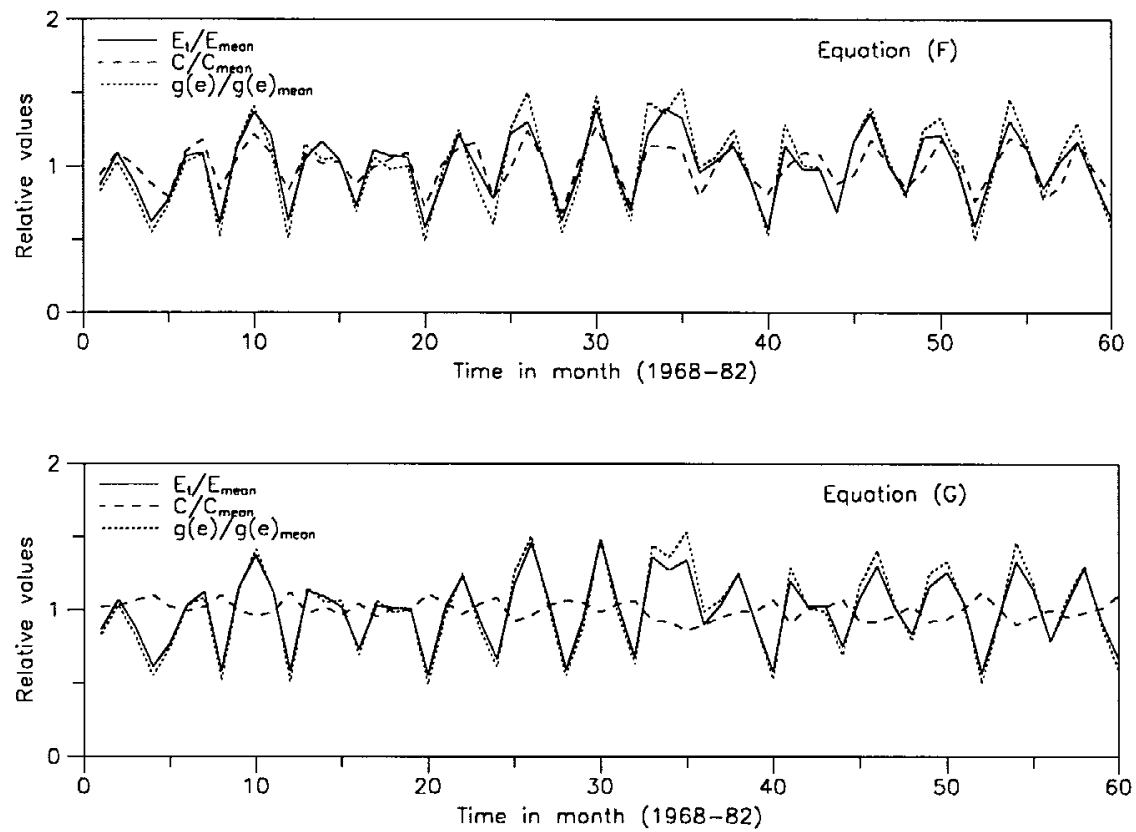

Figure 4. Relative values of computed monthly evaporation, aerodynamic conductance term, $C$ functions, and saturation deficit of air, $\left(e_{0}-e_{\mathrm{a}}\right)$ term in Equations $(\mathrm{A})-(\mathrm{G})$ versus time, for the Atikokan station
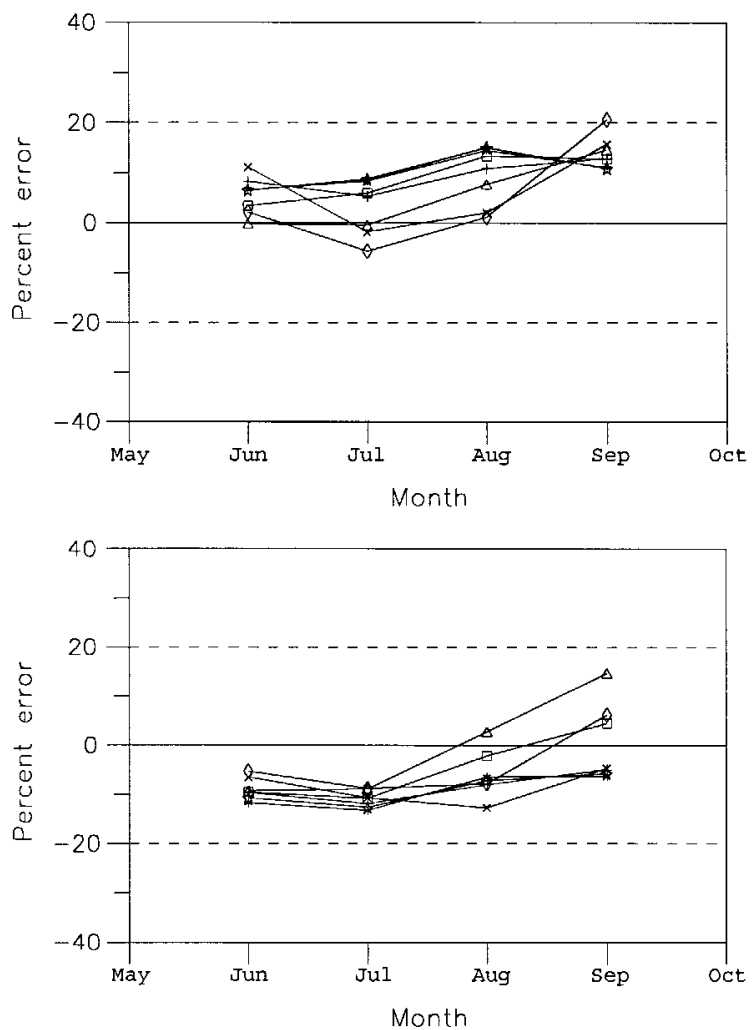

Figure 5. Per cent error in evaporation estimates for the independent test period at the Atikokan station. The top diagram shows the simulation for the period 1975-1982, and the bottom diagram shows the simulation for the period 1968-1974. [Line with asterisk for Equation (A), line with cross for Equation (B), line with plus for Equation (C), line with star for Equation (D), line with rhomb for Equation $(\mathrm{E})$, line with triangle for Equation $(\mathrm{F})$, line with square for Equation $(\mathrm{G})]$ 

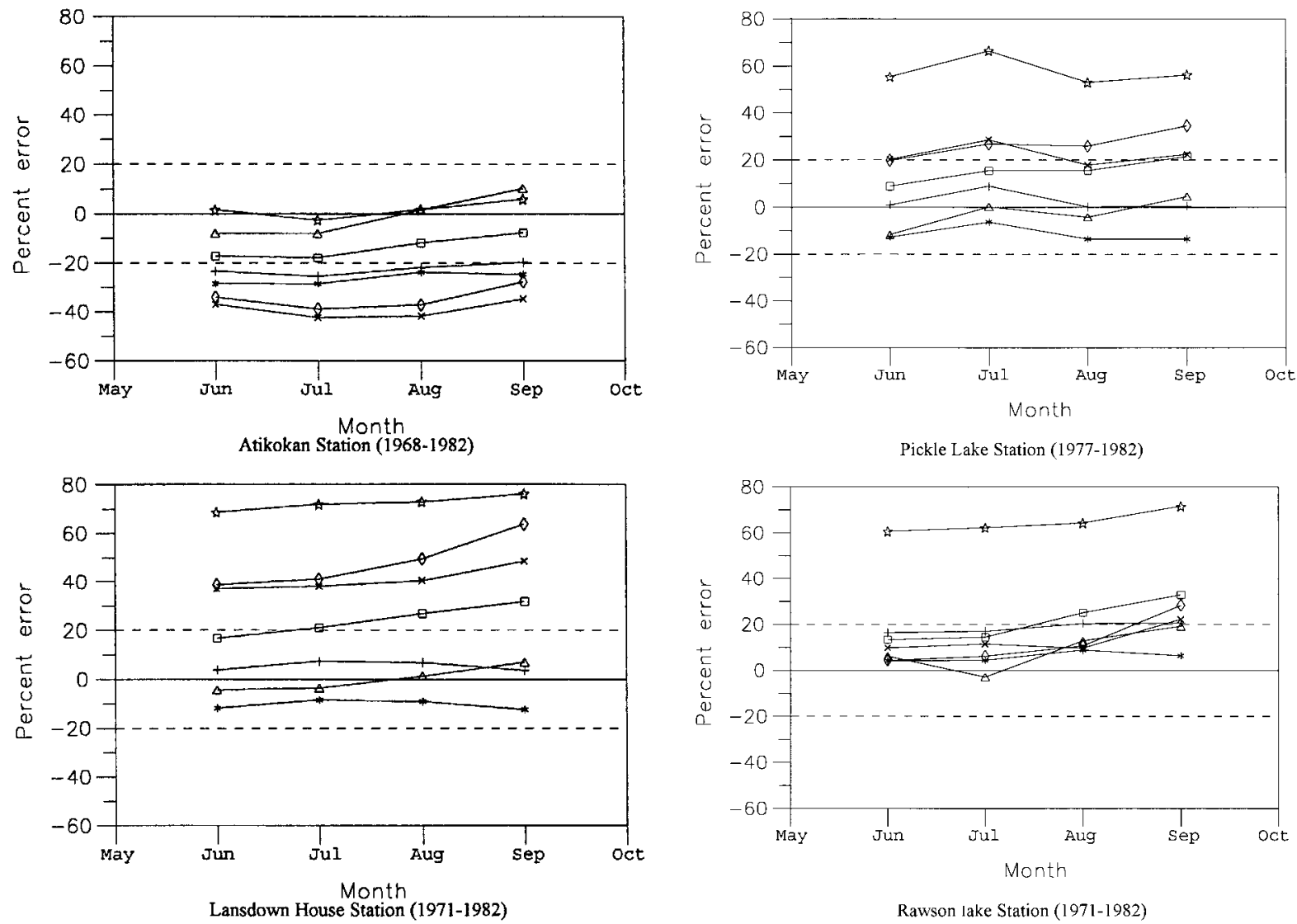

Figure 6. Per cent error in evaporation estimates at different climatological stations using regionally averaged parameters. [Line with asterisk for Equation (A), line with cross for Equation (B), line with plus for Equation (C), line with star for Equation (D), line with rhomb for Equation $(E)$, line with triangle for Equation $(F)$, line with square for Equation $(\mathrm{G})]$

\section{Model Verification}

The model verification study was carried out for the Atikokan station only, because the other three stations have relatively short data series (Table I). The sensitivity of the model parameters and model performance was studied using the split record procedure as proposed by Klemes (1986). The data series was split into two parts, 1968-1974 and 1975-1982, respectively. The seven models were calibrated separately for these two parts; the best parameter values were obtained for each calibration period as well as the period for the entire available record. Then, the parameter values obtained from the calibration on the first seven years (1968-1974) were used to simulate evaporation for the last eight years (1975-1982) of the available record and vice versa, to investigate the ability of the models to predict monthly evaporation for independent test periods. The results are shown in Figure 5. From an examination of Figure 5 it can be seen that the performance of the models in estimating evaporation for the independent test period is acceptable. The absolute value of seasonal per cent error varies from 2.45 to $9.96 \%$ and from 2.7 to $10.11 \%$ for the simulation of the second half and first half, respectively. The maximum monthly per cent error is $20 \cdot 63 \%$.

In general, the results of simulation indicate that, once the parameters are determined using the historical data for a station, the models can generally be used with sufficient confidence to estimate evaporation in the future for the same station.

\section{Regionalization}

The regionally averaged parameter values for the seven equations were used for each of the four stations to estimate evaporation. The results are shown in Figure 6 . If a relative error of $\pm 20 \%$ is used as an 
arbitrary measure of acceptance, all equations give unsatisfactory results for one or more stations. This means that an acceptance level of confidence cannot be achieved when transferring parameter values from one site to another, even within a not too big region.

\section{CONCLUSIONS}

Seven generalized equations for estimating evaporation, which encompass the 13 equations shown in Table I, were evaluated using climatological data in north-western Ontario, Canada. Calibration results show that all seven equations yield comparable and satisfactory estimates for monthly evaporation, provided the model parameters are calibrated using local meteorological variables. The saturation deficit of the air, i.e. term $g(e)=\left(e_{0}-e_{\mathrm{a}}\right)$ in Equation $(16)$, is the dominant factor in estimating monthly free water surface evaporation. Wind speed is found to be an insignificant factor for monthly evaporation. Model complexity is not necessarily a measure of its ability to perform better when using this type of equation.

Verification results indicate that there is a high degree of consistency in the parameter values for different calibration periods. This means that once the parameters are determined using the historical data for a station the equations can generally be used with sufficient confidence to estimate evaporation in the future for the same station.

The test on the feasibility of parameter transfer to another site shows that an acceptable level of confidence cannot be achieved even for such a small region with fairly similar climates.

\section{ACKNOWLEDGEMENT}

The authors thank Prof. U.S. Panu of Lakehead University for his kind assistance in providing all the necessary data and information and for giving permission to reproduce Figure 1.

\section{REFERENCES}

Bosen, J. F. 1960. 'A formula for approximation of saturation vapor pressure over water', Month. Weather Rev., 88(8), 275-276.

Brutsaert, W. H. 1982. Evaporation into the Atmosphere: Theory, History, and Applications. D. Reidel Publishing Company, Boston, Massachusetts.

Dalton, J. 1802. 'Experimental essays on the constitution of mixed gases: on the force of steam or vapour from water or other liquids in different temperatures, both in a Torricelli vacuum and in air; on evaporation; and on expansion of gases by heat. Manchester Lit. Phil. Soc. Mem. Proc., 5, 536-602.

Fitzgerald, D. 1886. 'Evaporation', Trans. Am. Soc. Civ. Eng., 98(HY12), 2073-2085.

Fritschen, L. J. 1966, 'Energy balance method', Proceedings, American Society of Agricultural Engineers Conference on Evapotranspiration and its role in Water Resources Management, December 5-6, Chicago, IL. St. Joseph, MI. pp. $34-37$.

Guitjens, J. C. 1982. 'Models of alfalfa yield and evapotranspiration', J. Irrig. Drain. Div. Proc. Am. Soc. Civ. Eng., 108(IR3), $212-222$.

Harbeck, G. E. 1962, 'A practical field technique for measuring reservoir evaporation utilizing mass-transfer theory', Geological Survey Professional Paper 272-E. US Government Printing Office, Washington, D.C. pp. 101-105.

Harbeck, G. E., et al. 1954. 'Water loss investigations, Vol. 1, Lake Hefner studies', U.S. Geological Survey Paper 269. US Government Printing Office, Washington, D.C.

Harbeck, G. E., et al. 1958. 'Water loss investigations, Lake Mead studies', U.S. Geological Survey Professional Paper 298. US Government Printing Office, Washington, D.C.

Haude, W. 1955, 'Zur Bestimmung der Verdunstung auf möglichst einfacher Weise', Mitteilungen des Deutschen Wetterdienstes, Nr. 11, Band 2. Bad Kissingen.

Helfrich, K. R., Adams, E. E., Godbey, G. E. and Harleman, D. R. F. 1982. 'Evaluation of the models for predicting evaporative water loss in cooling impoundments', Interim report no. CS-2325. Electric Power Research Institute, Palo Alto, CA.

Horton, R. E. 1971. 'Rainfall interception', Month. Weather Rev., 47(9), 603-623.

Hounam, C. E. 1971. 'Problems of evaporation assessment in the water balance', Report No. 3, on WMO/IHD Projects. WMO, Geneva.

Jensen, M. E. 1973. Consumptive Use of Water and Irrigation Requirements. ASAE, New York.

Klemes, V. 1986. 'Operational testing of hydrological simulation models', Hydrol. Sci. J., 31(1), 13-24.

Kohler, M. A., Nordenson, T. J. and Fox, W. E. 1955. 'Evaporation from pans and lakes', Weather Bureau Research Paper 38. US Department of Commerce, Washington, D.C.

Konstantinov, A. R. 1968. Evaporation in Nature. Leningrad.

Kuzmin, P. O. 1957. 'Hydrophysical investigations of land waters', Int. Assoc. Sci. Hydrol. Publ., 3, 468-478.

McCulloch, J. S. G. 1965. 'Tables for the rapid computation of the Penman estimate of evaporation', East African Agric. Forest. J., XXX(3), 286-295.

Meyer, A. F. 1915. 'Computing runoff from rainfall and other physical data', Trans. Am. Soc. Civ. Eng., 79, $1055-1155$. 
Meyer, A. F. 1944. Evaporation from Lakes and Reservoirs. Minnesota Resources Commission, St. Paul, MN.

Morton, F. I. 1968. 'Evaporation and climate: a study in cause and effect', Scientific Series No. 4. Inland Water Branch, Department of Energy, Mines and Resources, Ottawa, Canada.

Morton, F. I. 1990. 'Studies in evaporation and their lessons for the environmental sciences', Can. Wat. Resour. J. 15(3), 261-285.

Morton, F. I. 1994. 'Evaporation research - A critical review and its lessons for the environmental sciences', Crit. Rev. Environ. Sci. Tech., 24(3), 237-280.

Nash, J. E. and Sutcliffe, J. 1970. 'River flow forecasting through conceptual models Part I. A discussion of principles', J. Hydrol. 10, 282-290.

Panu, U. S. and Nguyen, T. 1994. 'Estimation of mean areal evaporation in Northwestern Ontario', Can. Wat. Resour. J., 19(1), 69-82.

Penman, H. L. 1948. 'Natural evaporation from open water, bare soil and grass', Proc. R. Soc. Lond., 193, $120-145$.

Rohwer, C. 1931. 'Evaporation from free water surfaces', Technical Bulletin 271. US Department of Agriculture, Washington, D.C.

Romanenko, V. A. 1961. 'Computation of the autumn soil moisture using a universal relationship for a large area', Proceedings, Ukrainian Hydrometeorological Research Institute, No. 3. Kiev.

Schulz, E. F. 1962. 'A graphical procedure to estimate potential evapotranspiration by the Penman method', Report CER 62 EFS49. Department of Civil Engineering, Colorado State University, Fort Collins, CO.

Singh, V. P. 1989. Hydrologic Systems, Vol. II, Watershed Modelling. Prentice-Hall, Inc.

Sutton, O. G. 1949. 'The application to micrometeorology of the theory of turbulent flow over rough surfaces', R. Meteorol. Soc., Quart. J., 75, (236).

Sverdrup, H. U. 1946. 'The humidity gradient over the sea surface', J. Meteorol., 3, 1-8.

Thornthwaite, C. W. and Holzman, B. 1939. 'The determination of land and water surfaces', Month. Weather Rev., 67, 4-11.

Van Bavel, C. H. M. 1968. 'Discussion of "Climate and Evaporation from Crops"', J. Irrig. Drain. Div., Proceedings, Am. Soc. Civ. Eng., 68, 533-535.

Visentini, M. 1936. International Association of Hydrological Science (IAHS). Publication No.22: 119-137.

Winter, T. C., Rosenberry, D. O. and Sturrock, A. M. 1995. 'Evaluation of 11 equations for determining evaporation for a small lake in the north central United States', Wat. Resour. Res., 31(4), 983-993.

$\mathrm{Xu}$, C.-Y. 1992. 'Monthly water balance models in different climatic regions', PhD Thesis, Vrije Universiteit Brussel, Hydrologie-22, Brussels $219 \mathrm{pp}$

Young, A. A. 1947. 'Evaporation from water surface in California: summary of pan records and coefficients, 1881-1946', Bulletin 54. Public Works Department, Sacramento, CA. 